\title{
ОЦЕНКА КОМПЛЕКСНОГО ВОЗДЕЙСТВИЯ ПОЛИГОНОВ ТКО НА БИОТОПЫ РЕК В УСЛОВИЯХ ВЛАЖНЫХ СУБТРОПИКОВ
}

\section{EVALUATION THE CSW LANDFILLS COMPLEX IMPACT ON RIVER BIO-TOPS IN HUMID SUBTROPICS}

\author{
N. Gudkova \\ T. Gorbunova \\ N. Matova
}

Summary. Effluent from Communal Solid Waste (CSW) landfills poses a serious environmental and social problem for natural watercourses, causing, in combination with other impact factors, the pollution threat for groundwater and the Black Sea coastal line. CSW effluents have complex chemical composition and their impact to the environment is not studied sufficiently. The authors on the Bytha River's example offer comprehensive approach to establishing systematic monitoring of landfill effluents impact to the natural ecosystems. A key role in this approach is played by integrated methods of biological indication, considering the dynamics of macroinvertibrates biocenoses and the water stream's general toxicity. Ecological state of the water stream sites was evaluated as a whole biotope, which includes wide range of geological, hydrological and physic- chemical aspects and subjected to multilevel pollution.

Keywords: Communal Solid Waste landfill, eutrophication, biotope, macroinvertibrates, integral bio-indicators.

\section{Введение}

4 ерритория Большого Сочи - это важнейшая курортная территория России, в значительной части относящаяся к зоне влажных субтропиков, что накладывает ряд дополнительных ограничений в обращении с отходами. Специфику этого региона составляет сложное инженерно-геологического строение, где активно протекают опасные геологические процессы - оползни, сели, эрозия и др. Активный промывной режим почво-грунтов за счет интенсивных атмосферных осадков приводит к тому, что не до конца разложившиеся органические вещества и другие примеси быстро попадают в водотоки и в прибрежную зону Черного моря, загрязняя их.

По этой причине серьезную экологическую проблему для водотоков в районе Большого Сочи представля-

\author{
Гудкова Наталья Константиновна \\ К.г.-м.н., С.н.С., ФГБНУ «Институт природно- \\ технических систем» (Филиал) г. Сочи \\ n.k.gud@yandex.ru \\ Горбунова Татьяна Львовна \\ Н.с., ФГБНУ «Институт природно-технических \\ систем» (Филиал) г. Сочи \\ tatianashaw@mail.ru \\ Матова Наталья Ивановна \\ К.э.н., С.н.С., ФГБНУ «Институт природно- \\ технических систем» (Филиал) г. Сочи \\ lelj06@yandex.ru
}

Аннотация. Стоки с полигонов ТКО представляют серьезную экологическую и социальную проблему для природных водотоков, оказывая, в сочетании с другими факторами воздействия, угрозу загрязнения грунтовых вод и прибрежной полосы Черного моря. Стоки ТКО сложны по химическому составу и их воздействие на среду изучено недостаточно. Авторами на примере реки Битха предложен комплексный подход к организации системного мониторинга влияния стоков полигона на природные экосистемы. Ключевую роль при таком подходе играют интегральные методы биологической индикации, учитывающие динамику биоценозов макрозообентоса и общую токсичность воды водотока. Экологическое состояние участков водотока оценивалось как единый биотоп, включающий широкий спектр геологических, гидрологических и физико-химических аспектов и подвергающийся многоуровневому загрязнению.

Ключевые слова: полигон твердых коммунальных отходов, эфтрофикация, биотоп, макрозообентос, интегральные биоиндикаторы.

ют собой стоки с полигонов твердых коммунальных отходов (ТКО), расположенные на склонах рек, в условиях влажных субтропиков.

Сложные по химическому составу стоки ТКО, которые, взаимодействуя с другими биотическими и абиотическими факторами, создают угрозу для естественных биологических сообществ рек и снижают эстетическую и рекреационную ценность водоемов в черте города. Рассмотрим влияние полигонов ТКО на природные гео-биотопы, применительно к условиям влажных субтропиков.

Лооский полигон ТКО расположен на правом склоне р. Битха, впадающей в Черное море, на абсолютных отметках 180-50 м, во второй зоне округа санитарной охраны города-курорта Сочи. Полигон официально существует с 1982 г., хотя неофициально 


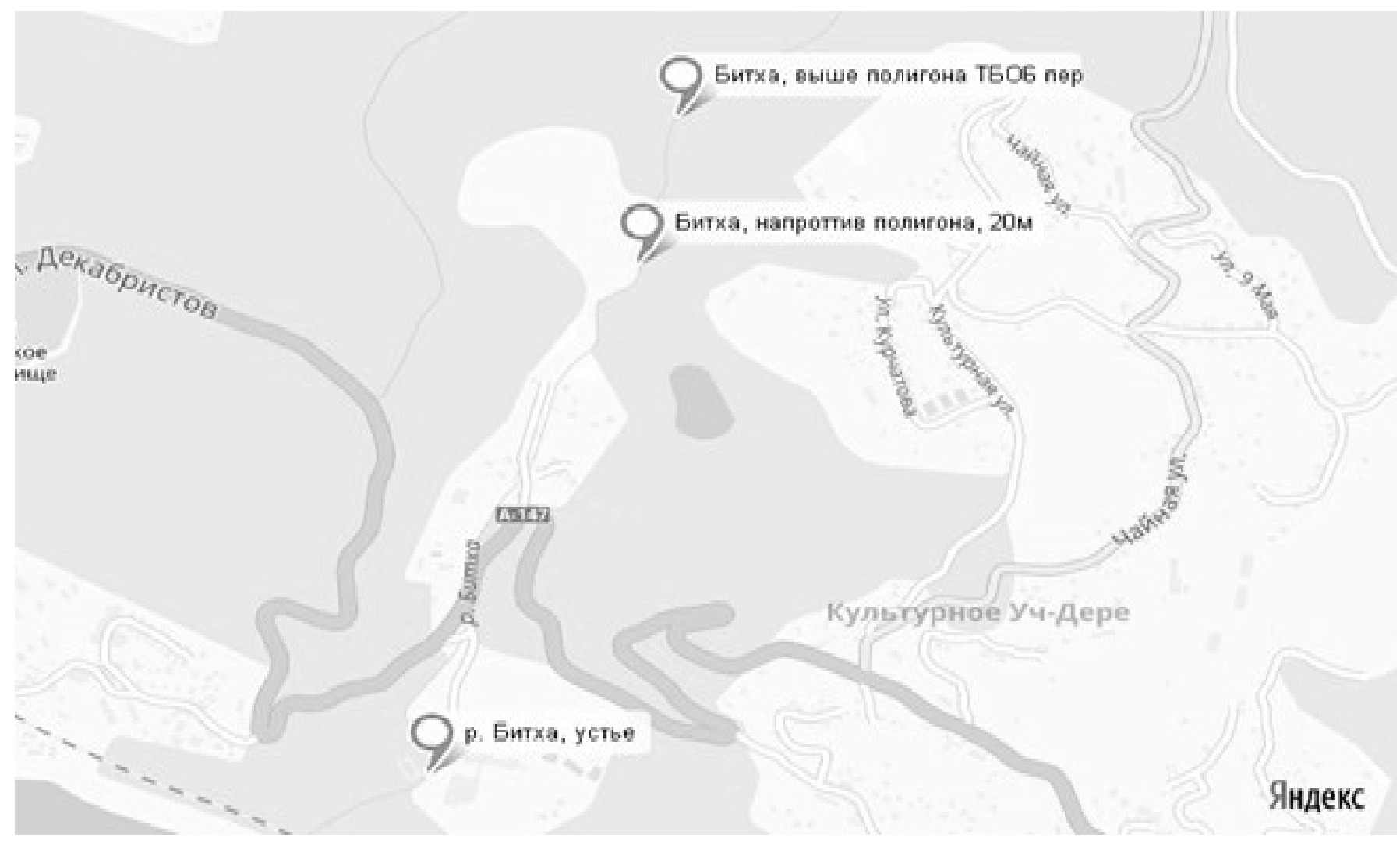

Рис.1. Схема отбора проб в реке Битха

складирование отходов здесь производилось и ранее. Функциональным назначением Лооского полигона ТКО была приемка, складирование и изоляция муниципальных твердых коммунальных отходов. За длительный период эксплуатации полигона, при значительных нарушениях требований к его устройству и содержанию, произошло загрязнение окружающей среды: почвы, донные осадки и поверхностные воды на всей прилегающей территории были загрязнены нефтепродуктами и тяжелыми металлами. Таким образом, неудачное расположение этого объекта на берегу р. Битха создавало целый ряд экологических и социальных проблем и оказывало устойчивое негативное воздействие на реку на протяжении многих десятилетий.

Полигон ТКО Лазаревского района г. Сочи многие годы является источником загрязнения природной среды в этом регионе. Это подтверждается несколькими исследованиями, включая работу 2011 г., проведенную в рамках программы исследования малых рек Черноморского побережья Кавказа. По данным этого исследования, фильтрат дренажных вод полигона вносит в р. Битха, впадающую в Черное море, значительный объем загрязняющих веществ как органического, биогенного характера, так и тяжелых металлов [3].
В более поздней работе ученых Института Океанологии им. Ширшова [4] также указывается на наличие тяжелого загрязнения органикой реки Битха и влияние этого загрязнения на прибрежную зону Черного моря в приустьевой зоне водотока. Так, например, было выявлено, что концентрация растворенных органических веществ в морской воде этого участка превышает фоновые значения более чем в 15 раз, а концентрации азота аммонийного - в 40 раз.

Степень опасности воздействия стоков свалочного фильтрата на окружающую среду может быть намного выше, чем влияние организованных промышленных стоков, ввиду их сложного комплексного состава, не выясненных токсических свойств стоков и потенциального их влияния на биоту водоемов [8].

Именно по этой причине вызывает беспокойство недостаточная изученность влияния полигона ТКО на речную и морскую среду и отсутствие научно-обоснованной системы мониторинга и оценки нагрузки на водоемы, прилегающие к местам утилизации отходов. Ключевую роль в таких исследованиях должны занимать методы биологического анализа и биоиндикации, позволяющие вовремя идентифицировать проблему и оценить воздействие различных факторов на среду комплексно. 
Целью данной работы является оценка и анализ экологической нагрузки полигона ТКО на природный водоток, в условиях влажных субтропиков, на примере комплексного исследования р. Битха. Комплексное исследование позволит определить изменения в природных биоценозах, вызванные воздействием поступления опасных фильтратов с полигона ТКО и провести зонирование водоема, основываясь на данных о состоянии его гидробиоценозов.

\section{Материалы и метолы}

Комплексное исследование р. Битха проводилось в период 2016-2018 гг. Пробы биологического материала из реки Битха отбирались на участке верхнего течения до взятия реки в коллектор, у выхода из коллектора в точке впадения в реку инфильтратов с полигона ТБО и в устье реки перед впадением ее в Черное море (рис 1).

Биологические анализы, произведенные в рамках этой работы, основываются на анализе качественного и количественного состава макрозообентоса водоема. На базе этих данных были вычислены интегральные биотические показатели - индексы QMCl, Маргалефа, Шеннона, Бергер-Паркера, рассчитанные по общеизвестным формулам [1]. Также определялся уровень хронической токсичности по Строганову с использование Dafnia Magna S. по 4-х бальной шкале на основе летального времени гибели 50\% тест-объектов (LT50) [6]. Для анализа просчитывались средние значения индексов, определенных в пробах, отобранных в 2016-2018 гг.

Гидрохимические данные были предоставлены лабораторией СЦГМС ЧАМ в рамках договора о сотрудничестве организаций. Кроме того, в рамках данной работы был проанализирован материал по изучаемому водному объекту, опубликованный ранее.

Важно отметить, что исследование воздействия полигонов ТKO на речные биологические сообщества ведется в рамках государственного задания по выявлению и апробации интегральных методов биоиндикации водных объектов для оценки экологического состояния водоемов и определения нагрузки на них от различных источников загрязнения. Эта работа будет продолжена в целях разработки мер по оздоровлению антропогенно нарушенных экосистем.

Результаты и обсуждение. Геологическое строение и антропогенная нагрузка. В геологическом строении района исследований принимают участие современные элювиальные отложения (кора выветривания), представленные глинами тугопластичными и полутвердыми (в необводненном состоянии) с щебнем песчаника и дресвой аргиллита. Мощность их изменяется от 2 до 10 м. Ниже залегает толщ трещиноватых аргиллитов верхнепалеогенового возраста. Мощность этой толщи по данным региональных исследований изменяется от 20 до 80 и более метров. Элювиальные глины и выветрелые трещиноватые аргиллиты при водонасыщении характеризуются резким снижением деформационных и прочностных свойств. Водонасыщение грунтов происходит по многочисленным трещинам, а разгрузка грунтовых вод - по ослабленным зонам на различной высоте склона. Для территории, где расположен полигон TKO, характерен высокий уровень залегания грунтовых вод. Уровень грунтовых вод находится на глубине 2,8 м. Преобладающими породами, подстилающими тело полигона TKO, служат суглинки и глины (обладающие слабой водопроницаемостью), часть фильтрата вытекает из свалочного тела, мигрируя с поверхностным стоком, попадая в водные объекты. Общая мощность глин и суглинков составляет 8 м. Территория расположения полигона ТКО характеризуется как оползнеоопасная.

Севернее полигона ТKО расположены особо охраняемые территории Сочинского национального парка, где развита только туристская и рекреационная деятельность. Антропогенная нагрузка минимальная. К северо-западу от полигона ТКО расположен поселок Нижнее Учдере. Кроме того, жилая застройка непосредственно примыкает к южным границам площадки, где расположен полигон ТКО. Этот участок реки испытывает значительную антропогенную нагрузку от не канализованного жилого сектора и ливневых стоков с автомагистрали. В устьевой части реки расположены лечебно-оздоровительные учреждения и пансионаты «Белые ночи», «Ивушка» и др. Негативное влияние полигона ТКО, обуславливающее значительное ухудшение условий проживания жителей ближайших населенных пунктов и отдыхающих, вызывает высокую социальную напряженность.

Значительную опасность представляет воздействие полигона ТKО на поверхностные воды из-за формирования в теле полигона антропогенных водоносных горизонтов. Основной источник поступления загрязняющих веществ в подземные и поверхностные воды - фильтрат. Формируясь в теле свалки, фильтрат скапливается в нижней части полигона ТKO [5].

Несмотря на частичную рекультивацию полигона ТКО и взятие реки Битха на значительной дистанции в подземный коллектор, фильтрат продолжает поступать в реку Битха. Объем поступающего в природный водоем фильтрата зависит от количества осадков и от характера материала, сконцентрированного на полигоне. Количество и качество фильтрата динамично изменяется с сезонной закономерностью: в зимне-весенний период количество фильтрата увеличивается, а в летне-осенний период уменьшается с динамикой, сходной с расхода- 


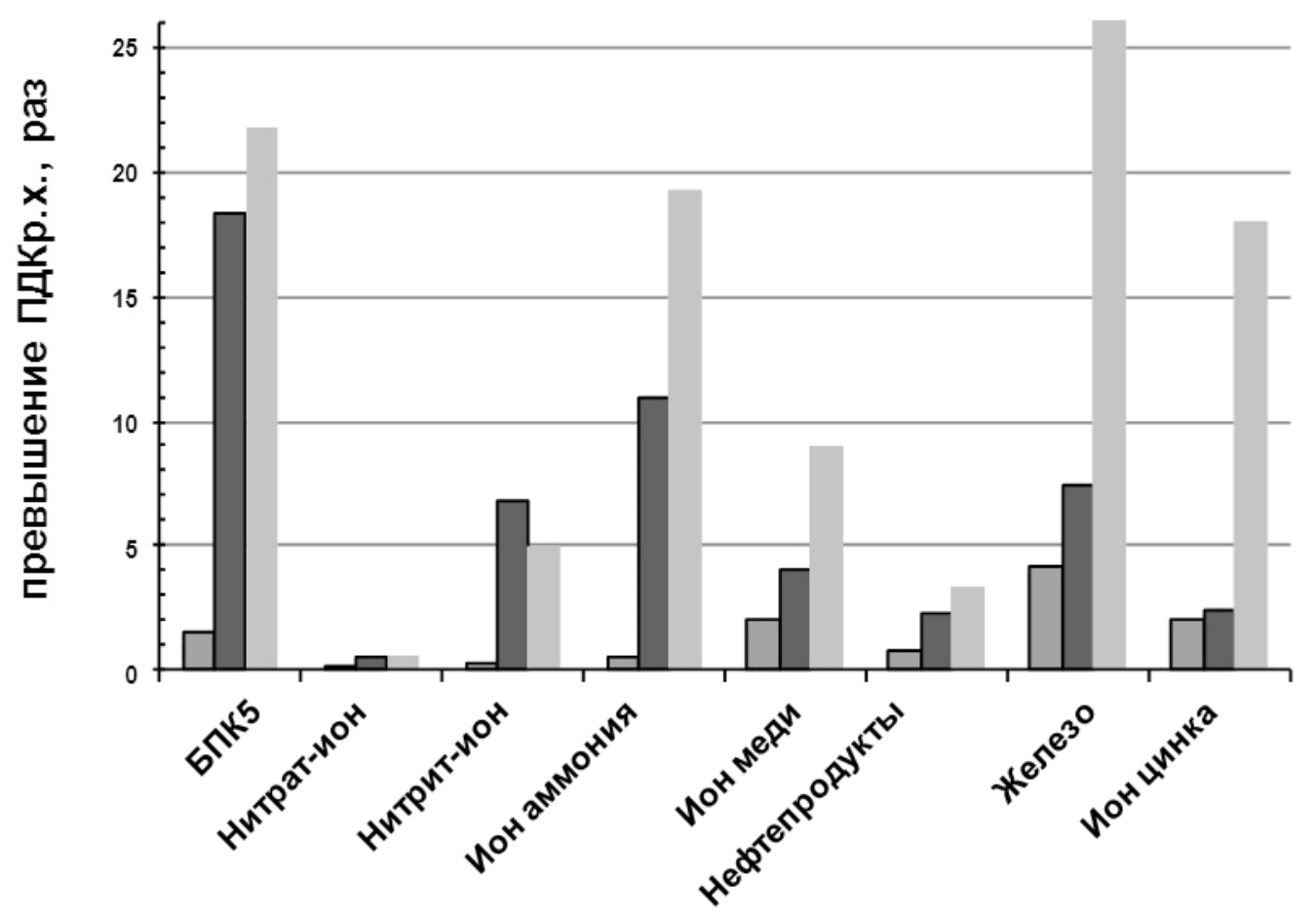

\begin{tabular}{|r|}
\hline ч. №1 \\
т. №2 \\
т. №3
\end{tabular}

Рис. 2. Диаграмма распределения концентраций загрязняющих веществ в р. Битха в контрольных точках по данным мониторинга 2010-2011 г.г.

ми рек. Соответственно в период интенсивных осадков и больших расходов рек количество органики в нем уменьшается. Наиболее концентрированный фильтрат и наименьший расход его наблюдается в период глубокой межени. Степень опасности воздействия таких стоков на окружающую среду может быть намного выше, чем влияние организованных промышленных стоков, ввиду их сложного комплексного состава, не выясненных токсических свойств и потенциального их влияния на биоту водоемов [8].

Предыдущими мониторинговыми исследованиями Лооского полигона ТКО, проведенными в 2010-2011 г.г., установлено значительное превышение нормативных показателей поверхностных вод и почв [5]. Наблюдение за изменением химического состава поверхностных вод в реке Битха в указанный период проводилось в трех контрольных точках, совпадающих с участками настоящего исследования. Фоновая точка № 1 располагалась в 100 м выше участка поступления фильтрата из полигона TKO, точка № 2 - напротив полигона TKO, в зоне выхода стоков фильтрата, точка № 3 была расположена в 100 м ниже полигона ТКО. На участке № 2 и № 3 вода р. Битха имела темно - бурый цвет и резкий неприятный запах.
На рисунке 2 представлена диаграмма распределения концентрации загрязняющих веществ в трех контрольных точках, по данным мониторинга 2010-2011 г.г.

В рамках исследований 2010-2011 г.г. было проведено опробование почво-грунтов в районе полигона ТКО. Из 18 проанализированных проб почво-грунтов 15 классифицируются как «допустимая» категория загрязнения, 3 пробы - «умеренно опасная» категория загрязнения. По валовому содержанию мышьяка, как вещества I класса опасности, 17 проб почв характеризуются опасной степенью загрязнения от 1 ПДК до 8,5 ПДК. По валовому содержанию веществ III класса опасности (ванадий) почвы в районе полигона ТКО характеризуются умеренно опасной степенью загрязнения. Содержание ванадия до 2ПДК. По марганцу отмечается превышение ПДК в 4 пробах - до 1,5 ПДК. Источником поступления загрязняющих веществ в почву является выход фильтрата из полигона ТKO.

Состояние биологических сообществ р. Битха. Биологические сообщества реки Битха характеризуются как креналь по Иллиесу. Этот тип объединяет биологические сообщества ручьевого комплекса с относительно небольшим расходом воды и шириной около 1 м в ме- 
Таблица 1. Значения биотических индексов и основных показателей факторов эфтрофикации р.Битха (средние показатели за период исследования).

\begin{tabular}{|l|l|l|l|}
\hline Проба & $\begin{array}{l}\text { Р. Битха, выше полигона } \\
\text { ТКО, фон }\end{array}$ & $\begin{array}{l}\text { Р. Битха, в месте } \\
\text { поступления фильтрата } \\
\text { с ТКО }\end{array}$ & Р. Битха, устье \\
\hline QМСІ & 5,47 & 4,3 & 3,53 \\
\hline Индекс Маргалефая & 8,47 & 5,29 & 2,89 \\
\hline Индекс Шеннона & 2,13 & 1,7 & 1,41 \\
\hline Индекс Бергер-Паркера & 0,42 & 0,47 & 0,56 \\
\hline Токсичность с исп. DМ по Строганову & 2 & 3,33 & 4 \\
\hline Степень заиления (шкала 1-5) & 3 & 4 & 5 \\
\hline Прозрачность & 27,67 & 4,67 & 10 \\
\hline Взвешенные вещества мг/л & 5 & 213 & 16,47 \\
\hline рН & 7,85 & 7,77 & 7,9 \\
\hline БПК5, мг/л О2 & 1,46 & 10,27 & 5,03 \\
\hline Азот аммонойный, мг/л & 0,01 & 0,68 & 0,62 \\
\hline Азот нитритов, мг/л & 0,01 & 0,33 & 0,18 \\
\hline Азог нитратов, мг/л & 0,14 & 2,17 & 0,97 \\
\hline Фосфаты, Мг/л & 0 & 0,01 & 0,01 \\
\hline
\end{tabular}

женный период. В таких водоемах обычно наблюдаются сочетание фрагментов твердых и мягких грунтов и смешение донных биотопов. Весной там может наблюдаться значительное разнообразие ручьевой фауны, где встречаются или доминируют лимнофильные, устойчивые к загрязнению виды. Летом, когда течение реки замедленно и наблюдаются гнилостные процессы, насекомые вылетают из водоема в виде имаго или погибают ввиду изменившихся условий. На смену им приходит бурное размножение видов, характерных для загрязненных, заболоченных водоемов (Aeshna, Asellus aquaticus, улитки болотного комплекса). Такие сообщества обычно относятся к $\beta$ - и а-мезосапобной зоне.

Участок реки в верхнем течении характеризовался чистым каменно-галечным дном, небольшим количеством песчано-илистых отложений и обрастаниями зелеными водорослями. В месте поступления в реку фильтратов с полигона ТКО (жидкость темно-коричневого цвета с характерным запахом) наблюдается мощный слой твердого коричневого осадка на камнях и донных отложения и отсутствие донной растительности. После разбавления речной водой, поступающей из коллектора, вода утрачивает коричневый цвет, однако на донных субстратах наблюдается желто-коричневый осадок и слизистые обрастания, характерные для водоемов, подвергающихся продолжительному воздействию органических загрязнений. В пробах, отобранных ниже автомагистрали и территории санатория «Белые ночи», речная вода была бесцветна, наблюдались илистые донные отложения и обрастания донного субстрата коричневыми и зелеными водорослями и слизью. Также во время отбора проб на этом участке был зафиксирован неорганизованный сброс в реку хоз-фекальных вод от располагающихся на берегу водоема поселений.

Исследование показало выраженное изменение биоценозов реки Битха на различных участках ее течения. В верхнем течении реки, до взятия ее в закрытый коллектор, водоем соответствует определению чистой реки высоким видовым разнообразием, на что указывают показания индексов Маргалефа и Шеннона (табл. 2). Этот участок характеризуется умеренным заилением донного субстрата, слабым органическим загрязнением и хорошим газообменом. Значение индекса QMCl указывает на происходящие на данном участке интенсивные процессы самоочищения, характерные для $\beta$-мезосапробной зоны. Слабая хроническая токсичность обнаруживалась только в период паводка. Анализ пробы в месте попадания в реку фильтрата с полигона TKO указывает на наличие тяжелого органического загрязнения: резко падает видовое разнообразие макрозообентоса, значение индекса QMCI свидетельствует о повышенной эфтрофикации, увеличивается доля проб с показателями хронической токсичности по выживаемости дафний. Поступающий в реку загрязненный сток не разбавляется до безопасного уровня, особенно в период летней межени из-за маловодности реки. Органика, содержащаяся в загрязненных стоках, аккумулируется в накапливающихся иловых осадках и обрастаниях, препятствуя развитию организмов-фильтраторов и обеспечивая условия для развития хирономид, моллюсков и олигохет, не требовательных к субстрату и устойчивых к эфтрофикации. Значения индексов видового разнообразия 
в устье водотока достигают минимальных значений, возрастают показатели токсичности воды. Хотя наблюдается снижение концентраций биогенов, БПК5 и взвешенных веществ в воде приустьевой зоны, биотические показатели говорят о деградации биоценозов (табл. 1).

На рисунке 3 отражено распределение в процентном соотношении к общей численности в пробе основных групп организмов макрозообентоса в пробах реки Битxa.

Рис. 3. Распределение в процентном соотношении к общей численности в пробе основных групп организмов макрозообентоса и перифитона в пробах р. Битха

В пробах верхнего течения и устья реки доминирующей группой являются двукрылые (Diptera). Однако в нижнем течение реки преобладает Chironomus plumosus, вид устойчивый к органическому загрязнению и принадлежащий к зоне полисапробности. Этот вид также был определен в месте впадения в реку стока TKO. В пробе, отобранной выше полигона, отряд Diptera представлен симилидами, которые характерны для чистой воды. Во всех пробах присутствуют представители отряда ручейников (Tricoptera). Однако только в фоновой пробе были определены четыре вида личинок ручейников, в пробах, подвергшихся загрязнению, было обнаружено только два вида этих насекомых. В пробе в месте попадания в реку стока ТКО преобладали олигохеты Tubifex Tubifex, обычные для водоемов с высоким уровнем органического загрязнения. В этой пробе отсутствуют поденки (Ephemeroptera). Хотя ниже по течению были обнаружены представители поденок и копепод, их численность была незначительной.

Деградацию водных биоценозов в устье р. Битха можно объяснить не только процессами аккумуляции загрязняющего вещества в донном осадке и биоте, но и дополнительной нагрузкой, оказываемой на реку неорганизованными хозяйственно-фекальными стоками и ливневыми смывами с автомагистрали. Так как река на значительном участке устьевой зоны протекает в бетонном коллекторе, процессы самоочищения не идут, и, ввиду вторичного загрязнения, вызванного декомпозицией накопившейся в русле органики, снижается насыщение воды кислородом.

\section{Зак^ючение}

В результате комплексного загрязнения р. Битха на всем ее протяжении, а также взятию реки в подземный коллектор, происходит деградация устьевых биоценозов водоема. На основе физико-химических и биологических данных, река может быть разделена на два различных по экологическому состоянию участка: зона верхнего течения, до сбросов фильтрата из полигона ТКО и устьевая зона - от точки сброса фильтрата до впадения реки в Черное море. На протяжении первого участка, до взятия реки в коллектор, ее биотоп соответствует типу кренали со сравнительно слабым органическим загрязнением. В отличие от него, в устьевой зоне наблюдаются признаки деградирующего биоценоза, с обедненным биоразнообразием, представленном несколькими толерантными к загрязнению видами и сильным заилением мягкого донного субстрата, аккумулирующим поступающую органику, токсиканты и продукты декомпозиции биоты. Такой биотоп соответствует палудогипокренали [7].

Воздействие на состояние водоема от такого многоуровневого загрязнения должно рассматриваться комплексно с учетом геологических условий, химических данных, учитывающих эффект адитивности поступающих в водоем токсикантов, биогенов, взвешенных веществ и динамику развития биологических сообществ. Необходимо принимать во внимание все биотические и абиотические факторы, влияющие на миграцию загрязнителей в среде. Такой анализ возможен при комплексном мониторинге реки, включающим гидрологический, физико-химический анализ воды и донных отложений и интегральные методы определения экологической нагрузки на гидробиоценозы.

Установлено, что загрязнение р. Битха происходит также ниже поступления стоков с полигона TKO, практически в устьевой зоне, непосредственно перед впадением ее в Черное море. Если потенциал самоочищения реки позволяет частично справиться с нагрузкой от стоков полигона ТKО, то после поступления органического загрязнения от не канализованного жилого сектора, ливневых стоков с автомагистрали и других загрязнителей, способность реки к самоочищению исчерпывается. Сравнительно небольшая река Битха вносит существенный вклад в загрязнение прибрежной полосы моря по органическому загрязнению и эвтрофикации среды.

Как уже отмечалось в наших предыдущих исследованиях [2], в настоящее время не существует систематизированной научно-обоснованной методики проведения комплексного мониторинга водоемов и прилегающих к ним полигонов ТКО, применительно к условиям влажных субтропиков. Исследование влияния стоков полигонов TKO, расположенных в зоне влажных субтропиков, на экосистемы естественных водоемов будет продолжено для идентификации и оценки их долгосрочного воздействия на окружающую среду и разработки программы мероприятий по минимизации негативного влияния полигонов ТКО на водоемы прибрежной полосы Черного моря. 


\section{ЛИТЕРАТУРА}

1. Горбунова Т. Л. Использование биотических индексов IMC и QIMC для оценки экологического состояния водотоков горного и предгорного кластера на примере рек на территории Большого Сочи // Инновации и инвестиции. — 2019. — № 2. — C. 110-117.

2. Гудкова Н.К., Горбунова, Т. Л. Оценка влияния стоков Адлерского полигона твердых коммунальных отходов на биоценозы реки Херота // Системы контроля окружающей среды.— 2017.— № 9 (29).—C. 115-121.

3. Доклад о состоянии природопользования и 06 охране окружающей среды Краснодарского края в 2011 году // Доклад Д 63.— Краснодар, Департамент природных ресурсов и государственного экологического надзора Краснодарского края. - 2012. - 360 c.

4. Завьялов П., Маккавеев П. Речные плюмы в акватории Сочи // Наука в России.—- Москва: ФГУ Академический научно-издательский, производственно-полиграфический и книгораспространительский центр «Наука».— 2014. — № 2. - C. 4-12.

5. Красовская С. П. Размещение отходов в условиях Черноморского побережья Кавказа: автореферат диссертации на соискание ученой степени кандидата технических наук. Москва. 2012. 24с.

6. Строганов Н.С. Методика определения токсичности водной среды //Методики биологических исследований /Под ред. Н. С. Строганова.- М:.--1971.C. $14-60$

7. Чертопруд М. В. Реофильные сообщества макробентоса Северо-Западного Закавказья // Материалы IV Всероссийского Симпозиума по амфибиотическим и водным насекомым и X Трихоптерологического Симпозиума.—Владикавказ: СОГУ.- 2010.—C. 131-135.

8. Crowley D., Staines A., Collins C., Bracken J., Bruen M., Fry J., Hrymak V., Malone D., Magette B., Ryan M., Thunhurst C. Health and environmental effects of landfilling and incineration of waste — a literature review. Dublin: Dublin institute of technology. Report 3. - 2003.— 284 p. URL: http://arrow.dit.ie/schfsehrep/3 (дата обращения 25.07.2020).

(с) Гудкова Наталья Константиновна (n.k.gud@yandex.ru),

Горбунова Татьяна Львовна ( tatianashaw@mail.ru ), Матова Наталья Ивановна ( lelj06@yandex.ru ).

Журнал «Современная наука: актуальные проблемы теории и практики»

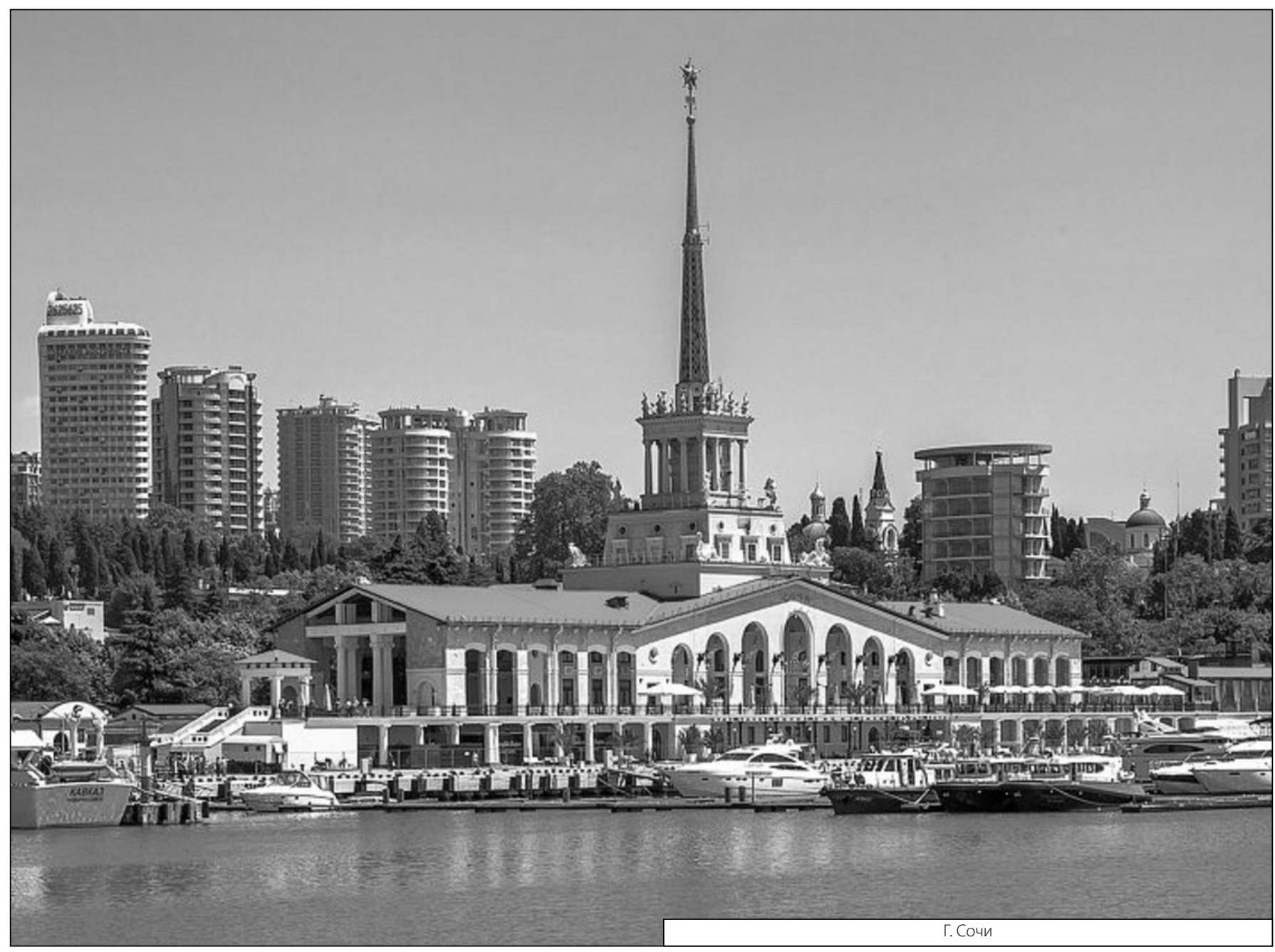

